\title{
The Invisible Culture of Discrimination
}

Call it 'institutional racism or unconscious bias, it has devastating impact on the victims

\author{
Satheesh Mathew MBBS MD FRCPCH \\ Consultant Neonatologist, Barts NHS Trust, London \\ Vice President, British Association of Physicians of Indian Origin \\ satheesh.mathew@gmail.com
}

\section{Key words}

Institutional racism, discrimination, race relations, BAME

cite as: Mathew S. The Invisible Culture of Discrimination. Call it Institutional racism of unconscious bias, it has devastating impact on the victims. Sushruta 2019 (Nov) 23-25 ePub 22.11.2019 DOI: $\underline{10.38192 / 12.1 .13}$

A recent ITV news item featured Radhakrishna Shanbag, a senior surgeon with over 20 years of service in the NHS, being asked, 'Please can I have a white doctor for my operation?', by one his patient's ${ }^{1}$. Any form of racism is both painful and upsetting, however to a dedicated professional it throws a much greater challenge. To remain professional, composed and objective in the face of adversity, is ingrained in medical training. One is also expected to provide the very best of care 'free from all bias' at all times to all comers. As in this case, professionals have no choice but to swallow the insults and provide alternatives to get the best possible outcome, suppressing the impact on self-worth and devastating emotional trauma.

The surgeon, while experiencing blatant exhibition of 'racism', seemed more to me in a predicament as he explained in a media interview, with and uncertainty about how the organisation would support him. It is indeed worrying, if a highly trained professional, after two decades of service appears to have limited confidence in the NHS, when it comes to dealing with overt form of racism. However, after the this item was aired there has been a small twitter storm of opinions in support of the surgeon, clearly condemning this behaviour and prophesying that NHS has a zero tolerance policy to any form of abuse towards staff. There have also been \#metoo stories of other professionals facing similar abuse in their own workplace.

There is a another hidden side to discrimination that is perceived but often not understood or able to be clearly demonstrated. Yet feared equally with far more impact on the career and personal lives of doctors, nurses and other healthcare staff. Often this is manifest in the form of poor supervision, level of mentorship/ support and opportunities for progressing careers. The NHS Workforce Relations Equality Standard Report in $2018{ }^{2}$ highlighted the continued nature of the under- representation of Black \&amp; Minority Ethnic (BAME) staff in higher positions in the NHS. 
This is compounded by the trend in the NHS of the deterioration in the working conditions often leading to recognised unsafe scenarios for care delivery. Often this is related to lack of adequate resources. While I endorse these concerns, the real challenge lies in the systemic failures in ensuring that monitoring and accountability structures are robustly implemented across the NHS.

Over the years, British Association of Physicians of Indian Origin, has been inundated with inquiries and requests for advice and support from international medical graduates (IMG) at all grades and seniority. The most common among these, were the for the fear of discrimination and seeking appropriate mentorship. Many IMGs were concerned that the available organisational support structures were lacking in empathy and cultural competency. There was a perception of not being dealt with in fairness or openness expected universally. More came to light when BAPIO, supported by many other organisations successfully petitioned the High Court against the attempt of the Government to introduce unfair and retrograde immigration rules. The changes in the "Highly Skilled Migrant Programme" ("HSMP") would have impacted on the careers of over 14,000 professions, many of whom would have been sent out without qualification or a career under this proposed rule. Professional trade union structures failed to provide appropriate support. BAPIO decided to establish a not-for profit professional support organisation in 2010 as the Medical defence Shield (MDS). A project for doctors and run by doctors that is focussed on fairness and justice for all doctors in difficulty.

BAPIO, remains committed to 'patient care and safety'. We support leadership and professional excellence for all doctors including IMGs and doctors from black and the other minority ethnic backgrounds to strive to maintain high healthcare professional standards. And we are proud that these IMGs have been making significant contribution to sustain and develop the NHS. There was a strong demand for BAPIO to make its presence felt across the country. Over the years, we have developed a network of regional offices.

The recent case of 'Bawa-Garba' has reopened a pandora's box of a number of systemic failures that the NHS has not been able to address. ${ }^{3}$ The NHS and the regulatory bodies have a responsibility to ensure that working conditions are safe for both patients and the staff that care for them. We have welcomed the NHS Long-Term Plan and its commitment to supporting NHS Workforce Race Equality Standards.

There is often a historical lack of trust in the processes of openness and fairness within traditional institutions. The NHS is not immune to this and hence the impact of this perceived institutional unfairness needs to be acknowledged by senior leadership and a clear message given to remove the culture that condones the discrimination; institutional, direct and indirect or covert of unconscious bias.

We hope that the Interim NHS People Plan (within the NHS Long-Term Plan) ${ }^{4}$ would invest in the wellbeing and support to the whole workforce and in doing so remove barriers to progress for all staff irrespective of their race, religion, sexual orientation or ethnicity including protected characteristics. To propagate a culture shift in the NHS governance structure that 
is both robust and sensitive to the needs of its employees; to enable them to deliver high quality care in a safe and just environment.

1. https://www.itv.com/news/2019-10-31/can-i-have-a-white-doctor-for-the-operation racist-abuse-against-nhs-staff-almost-triples-itv-news-finds/

2. https://www.england.nhs.uk/wp-content/uploads/2018/12/wres-2018-reportv1.pdf

3. David Oliver: Should NHS doctors work in unsafe conditions? BMJ 2018;360:k448

4. https://www.longtermplan.nhs.uk/wp-content/uploads/2019/05/Interim-NHS-

People-Plan June2019.pdf 